\title{
5S system as a manner for improving working conditions and safety of work in a production company
}

doi:10.2478/mape-2019-0050

Date of submission to the Editor: 06/2018

Date of acceptance by the Editor: 07/2018

MAPE 2019, volume 2, issue 1, pp. 496-507

Patrycja Kabiesz

ORCID ID: 0000-0001-5920-7485

Joanna Bartnicka*

ORCID ID: 0000-0003-1639-5804

Silesian University of Technology, Poland

\section{INTRODUCTION}

The basic duty of every employer is to ensure two things that are dedicated to both: internal customer in the field of safety working conditions, and external customer in the field of the quality of manufactured products that must meet the customer's expectations. Currently, customers have higher and higher product requirements and impose a high standard of employee safety, which means that a number of legal requirements must be met at the same time (Bayo-Moriones et al., 2010, Paszkowski and Loska, 2018). Various management systems are implemented in enterprises, which strive to improve results in order to increase the competitive advantage what is strictly connected to two factors: efficiency and effectiveness. To improve the efficiency and effectiveness of management, different strategies based on the lean manufacturing philosophy are used (Bevilacqua et all., 2015). One of this strategy is implementing $5 S$ method. The name $5 S$ is an acronym of five Japanese words beginning with the letter "s": seiri - sort, seiton - straighten, seiso - shine, seiketsu standardize, shitsuke - sustain (Al-Aomar, 2014; Ramdass, 2015; Patel and Thakkar, 2014).

The first step in implementing this method to the enterprise is sort. The sort consists in the elimination of unnecessary tools, unused equipment and machines, damaged components, products and documents. At the workplace, there should be only the necessary items needed during the production process (Kaushik Sanjeev, 2012). The next stage is straighten, which aims to arrange all necessary items so that they can be easily selected for use. Next step "shine" means keeping the workplace clean, particularly from unused tools and materials. Standardize is responsible for maintaining everything in order and according to standards and procedures for all. The last, most difficult stage is self-discipline that is developing a habits of observing the implemented rules and to react to any deviation from the $5 \mathrm{~S}$ rule. (Korkut et al., 2009). This method supports the process of improving working conditions, proper process flow and ensures safety of work. The most important goal of this method is to systematize activities that should be performed in a specific way to introduce good habits that improve the working conditions and improve the efficiency of production.

\footnotetext{
*joanna.bartnicka@polsl.pl
} 
According to (Ablanedo-Rosas et al., 2010) this method brings the following benefits:

- Reduced costs and better utilization of materials,

- Increased the productivity by reducing waste of time looking for objects. Keep only the essential items for the work that is being done,

- Improvement the machine condition,

- Improvement the quality of product and services,

- Reduction in the number of Safety Incidents,

- Improvement the culture, have more.

The $5 \mathrm{~S}$ method is a long-lasting process that reorganizes the entire enterprise to improve various areas of activity, but above all the safety of employees and the quality of finished products.

The aim of the article is to present the implementation of the $5 \mathrm{~S}$ method in a production enterprise, thanks to which there was an increase in safety at workplaces and improvement of product quality. Innovative ways of conducting internal audits were presented and a model for implementing the $5 \mathrm{~S}$ concept was proposed, which supports maintaining a high standard in the company.

\section{STAGES OF IMPLEMENTATION OF 5S METHOD}

The implementation of the $5 \mathrm{~S}$ method consists of five separate stages. In order to talk about the effective implementation of the method and benefits resulting from its implementation, the activities within each stage must be properly performed and maintained in the enterprise (Mazur et al., 2010). Figure 1 presents the stages of implementation of the $5 S$ method, the scope of tasks in individual stages and the method of combining individual stages.

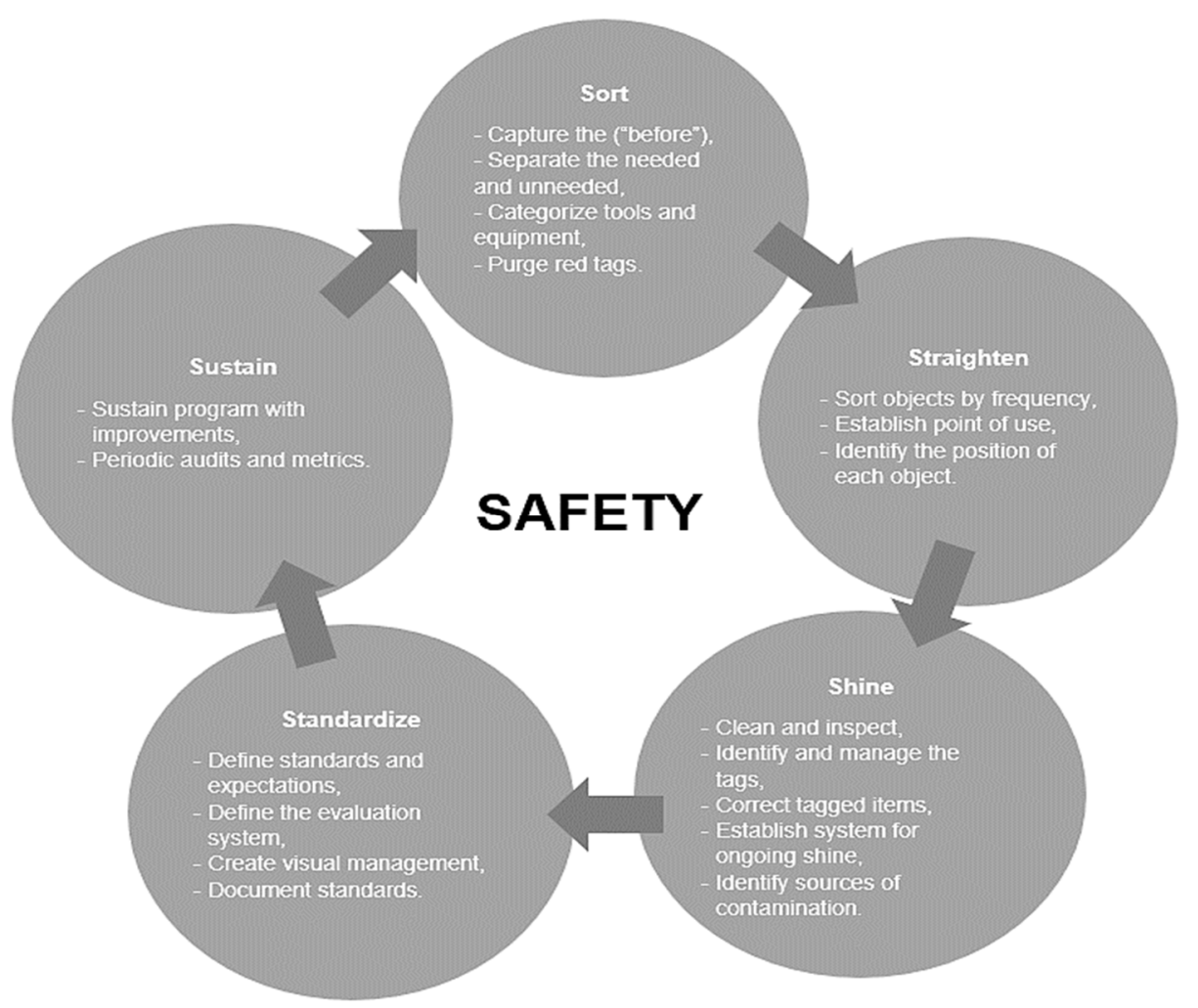

Fig. 1 Stages of implementing the $5 S$ method 
It is worth paying attention to the universality of the model, which can be used in a small, medium and large enterprise, as well as at home or at school (Kobayashi et al., 2008). It is worth noting that the implemented 5 S system in the enterprise should be supervised by the implementation team, which consists of the Plant Director, manager, leader and specialists. Before starting the implementation of the system, all employees of the company must be trained in the 5S method and informed about the schedule of events related to the implementation of the system.

\section{Sort}

Work on a dirty, crowded and unorganized position does not affect positively on quality, safety and work efficiency. At this stage, unnecessary items should be identified and removed from the workplace. The purpose of this action is to remove the mess and free up space and allow the organization of the necessary items. In order to eliminate unnecessary items at the workplace, you should carry out tagging, which will only recognize the tools and things need. Unnecessary or spoiled tools and objects are marked colorful tags (Chapman, 2005). Tagging gives the possibility of communication between employees about specific items. Next, a list and analysis of the entire workplace equipment should be drawn up (Fig. 2), and then the workplace should be sorted out according to the data sheet.

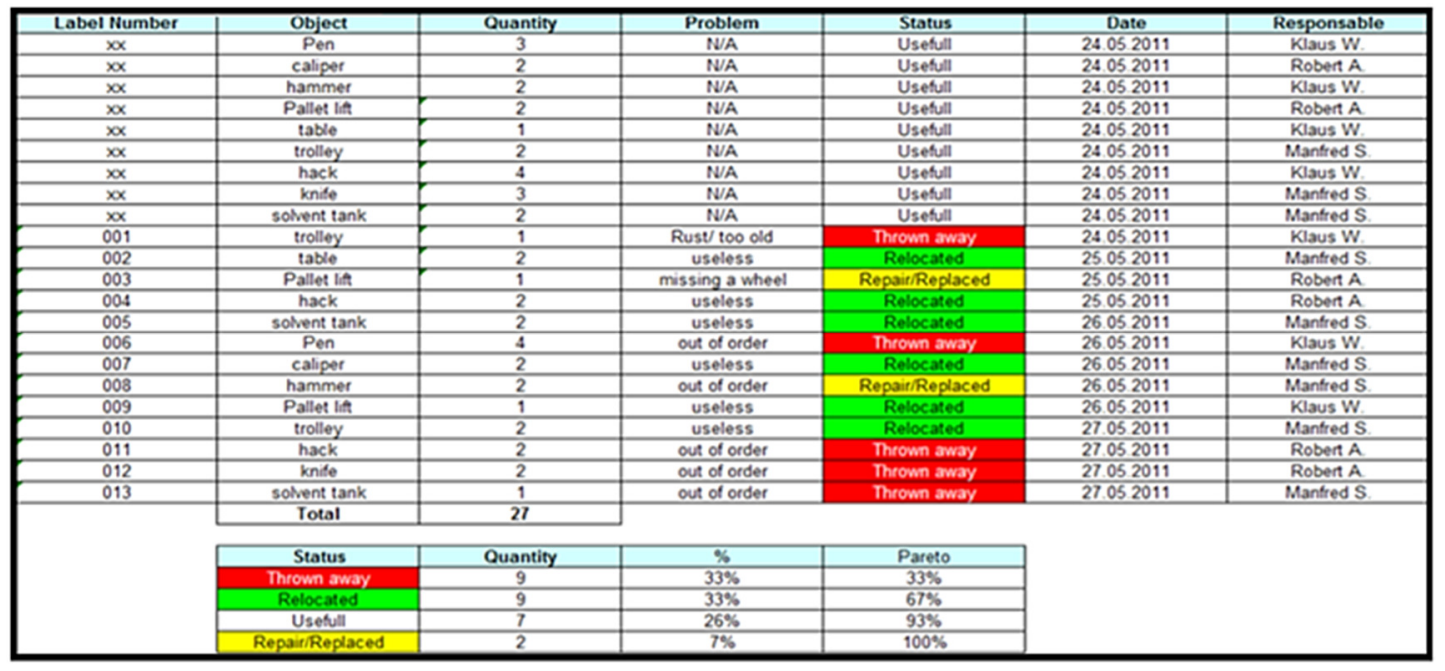

Fig. 2 An example data sheet with workplace equipment

After implementing the first stage, the following baskets are visible in the company:

- Eliminating worn or damaged tools that may have a negative impact on product quality and work safety,

- More space at the workplace,

- Finding lost tools,

- Elimination of unnecessary stocks.

As part of this stage, you may have a problem with:

- Negative attitude and resistance of employees to implement changes,

- Identification and marking of things needed and unnecessary,

- Communication between employees, 
- The authority of the management staff introducing the 5S method among employees.

The various sorting stages are shown in Figure 3.

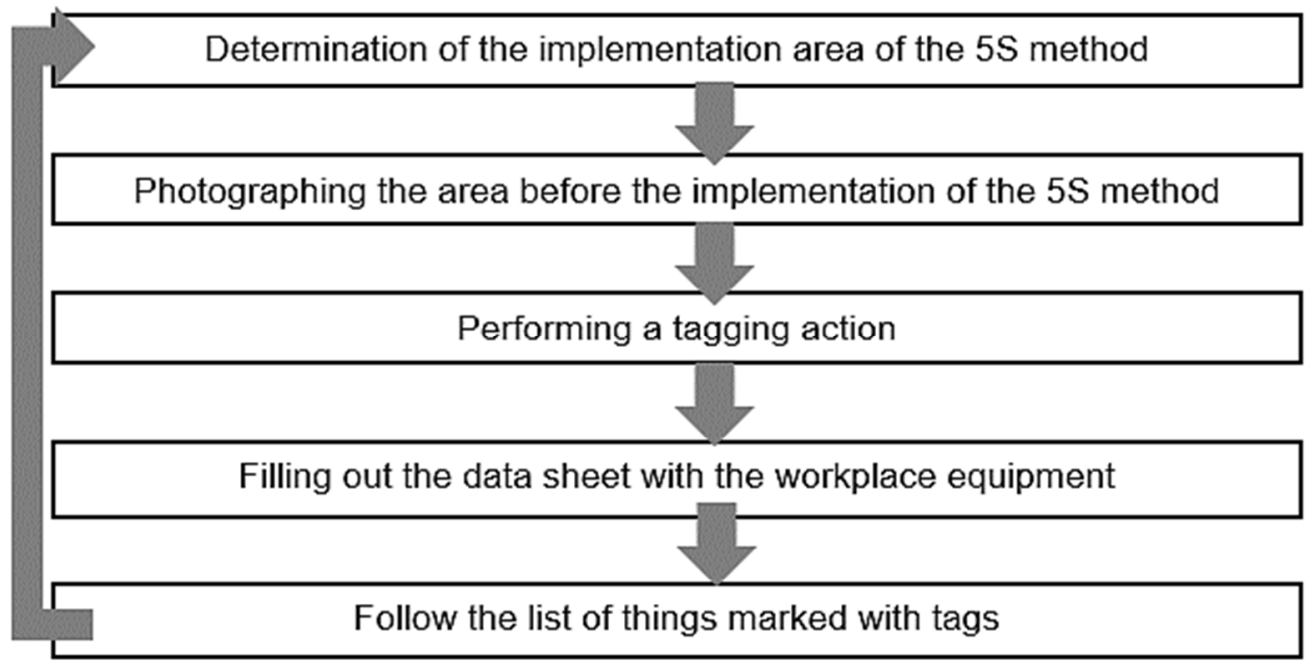

Fig. 3 Individual sorting steps

\section{Streighten}

The second stage of the $5 \mathrm{~S}$ method is the systematics of the workplace, which consists in the proper organization of the necessary objects at the workplace. There are strictly defined places where production items will be located. The location of objects and tools is determined on the basis of frequency of use and workflow, taking into account safety and ergonomics of work. The correct placement of things is important at this stage to eliminate unnecessary movements, and the removal of tools was easy and convenient for the employee. Place items used more often in an easily accessible place, at arms and elbows, while items that are used less frequently should be placed further. All items should be grouped according to accepted criteria and placed in tool boxes, suitcases. Place the items clearly, for example, using colored lines or shades. Figures 4 and 5 present the area before and after the implementation of the method.

The most important benefits of this stage include:

- Eliminating the waste of time and energy needed to find and download tools,

- Saving space at the workplace, where only the necessary tool needed for production is located,

- Increase production efficiency by eliminating waiting and searching for tools,

- Proper placement of the workplace taking into account ergonomic factors, including the elimination of unnecessary torso movements, elimination of manual transport.

As part of this stage, you may have a problem with:

- Costly reorganization of the workplace,

- Limited space at the workplace and difficulties in properly positioning the workplace. 


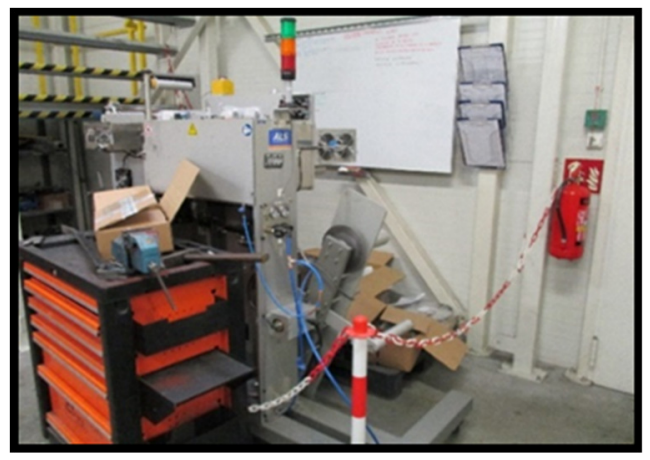

Fig. 4 Area before implementation of the $5 S$ method

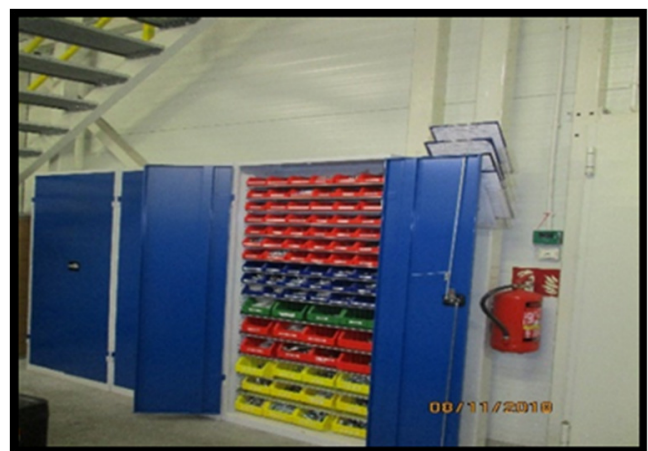

Fig. 5 Area after implementation of the $5 S$ method

\section{Shine}

Shine it is a process for eliminating dirty, grime and maintaining through intensive checking. The aim of the process is ensure that the process is brought back to as good as new condition and easily kept that way.

Cleaning has meaning, because maintaining a clean area allows you to get a lot of positive results:

- Inspection during cleaning,

- Understand sources of contamination,

- A visual standard to be able to see if conditions change,

- Clear standards for what should be cleaned and checked/when.

As part of this stage, you may have a problem with:

- Lack of time for precise and thorough cleaning of the whole workplace,

- Maintaining cleanliness and order at the workplace.

\section{STANDARDIZE}

Standardization allows you to maintain all changes established during conversations in the first three stages of the $5 S$ method. The responsibility of the employees for the individual components of the system should be determined. In addition, all rules of the 5S standard should be saved using e.g. training manual, on the job training, method sheet, work instruction, visual workplace systems, one point lesson.

Employees should be accounted for their duties and tasks. One of the employee assessment tools is the audit, which assesses the degree of fulfillment of the implementation of the 5 S method.

Benefits resulting from the implementation of the stage: 
- Guarantee of maintaining the implemented system,

- Responsibility of the employee for the activities performed.

Incorrect implementation of the fourth stage can lead to:

- Re-soiling the workplace,

- Reduction of production efficiency,

- Return to old habits,

- Discouragement of employees.

\section{SUSTAIN}

The last, most important stage is self-discipline, which depends on employees to a large degree. Thanks to self-discipline and high employee awareness, the system will be constantly maintained and improved. Management plays an important role at this stage, which should motivate employees. At this stage, the management should answer the following questions:

- Are all stakeholders engaged?

- Are we addressing the root cause?

- Does everyone know what to do and when to do it?

- Can we do the same thing every time regardless of who does it?

- Is it obvious to everyone when it does not happen?

- Can we do it forever?

\section{METHODOLOGY AND DISCUSSION}

The methodology is divided into three main stages:

1. Development of theoretical model for implementing $5 S$ methods.

2. Conduction of diagnosis and definition of corrective actions in a given company.

3. Development of a tool for supporting implementation of $5 S$ method in a given company.

The idea of the research is to integrate theoretical and practical aspects of $5 \mathrm{~S}$ methodology that could be start point for development of useful and unify method for improving working conditions and safety of work in a company.

\section{A company description}

The research was carried out in a production company that deals in the output of unit packaging made of paper for the food industry and gastronomy. The plant with an area of $10600 \mathrm{~m} 2$ has: flexographic printing with rollers, offset printing on sheets, cutting machines, adhesive machines and other finishing machines. The company employs approximately 120 production workers and approximately 25 office employees. By maintaining the highest standards of quality, hygiene and safety, the company is a partner of the largest international and domestic producers of dairy products, ice cream and fats and leaders in the nutrition and retail trade.

\section{Theoretical model of $\mathbf{5 S}$ method}

The 5S method consists of five simple steps that can be easily implemented into an enterprise. However, there is no universal model that could support this implementation in effective and efficient way. In the Figure 6 a proposed implementation reference model is presented that include all necessary steps for 
using $5 S$ method effectively and efficiently. The model encompasses the theoretical aspects of implementing all assumptions included into 5S method.

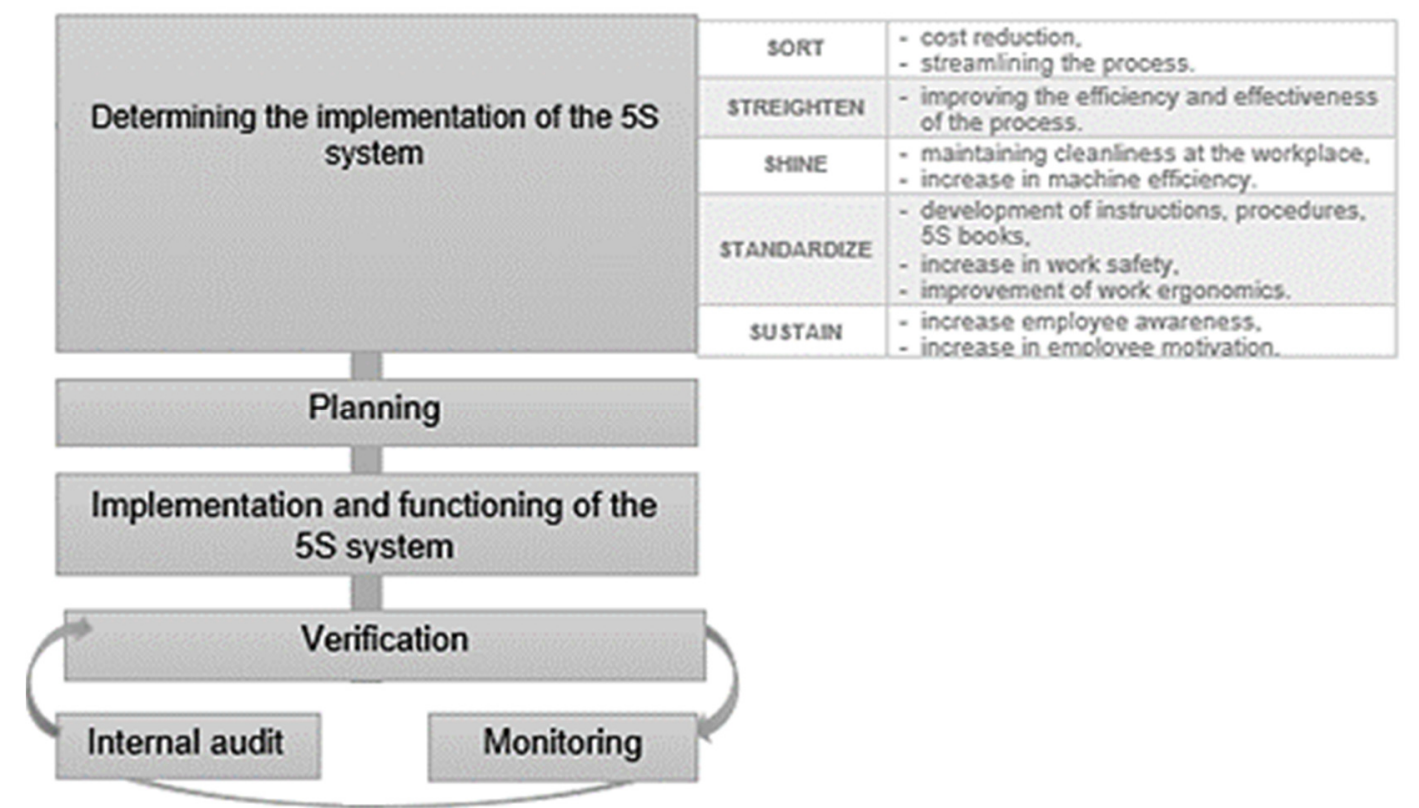

Fig. $65 \mathrm{~S}$ method theoretical model

Before starting the implementation of the $5 S$ method, it is needed to specify the implementation goals, which are formulated separately for each stage (see Fig. 6). Then the selection of an appropriate method that will support the implementation of the $5 \mathrm{~S}$ system is made. One of the implementation methods is an audit which includes a detailed analysis of the performance of the given company. The audit may be carried out by independent, certified specialists and experts (external audit) or by designated employees of a given company (internal audit). The aim of the audit is to assess the company in terms of the adopted criteria, e.g. legal compliance, implementation of standards and procedures, internal company requirements, quality of the raw material / finished product or financial stability of the company. The main audit tasks include the detection of nonconformities. The audit serves as an information and advisory role for the management and managerial staff (Abbott et all., 2010).

A properly conducted audit largely affects the efficiency and effectiveness of the $5 \mathrm{~S}$ system and the activities of the entire organization. The method of conducting the audit is of key importance. It quickly diagnoses and analyses the degree of meeting legal requirements as at the day of the audit. Each properly conducted audit consists of 7 stages, i.e.:

- initiation of an audit,

- audit review,

- preparation of audit activities,

- carrying out activities,

- preparation of an audit report,

- completion,

- carrying out audited activities.

Due to the number of stages and their wide scope, this is a time-consuming tool, but it effectively maintains and improves standards and increases employee involvement. 


\section{Diagnosis and definition of corrective actions}

According to specific goals formulated at the first stage of the research methodology a comprehensive diagnosis in the company was performed. The diagnosis tasks covered all workstations which were:

- flexographic printing with rollers,

- offset printing on sheets.

The results provided an assessment outcomes of current working conditions and was the base for defining necessary corrections. Both the diagnosis outcomes and corrections were analysed and ordered by 5 fields according to $5 S$ methods that were a basis for developing an internal audit template. Particularly the diagnosis and propositions of corrections are presented in the Table 1.

Table 1

The results of the diagnosis and the proposal to improve the workstations.

\begin{tabular}{|c|c|c|}
\hline \multirow{5}{*}{$\begin{array}{l}\text { Diagnosis - } \\
\text { defining } \\
\text { the } \\
\text { necessary } \\
\text { permissions }\end{array}$} & SORT & $\begin{array}{l}\text { - reduction of stocks, } \\
\text { - better use of the workspace, } \\
\text { - preventing the loss of objects. }\end{array}$ \\
\hline & STREIGHTEN & $\begin{array}{l}\text { - shortening the time of looking for things at the workplace, } \\
\text { - improvement of work safety, } \\
\text { - improvement of work efficiency. }\end{array}$ \\
\hline & SHINE & $\begin{array}{l}\text { - improvement of machines' efficiency, } \\
\text { - maintaining a clean and spatial workplace, } \\
\text { - quick information about machine damage, } \\
\text { - elimination of causes of accidents. }\end{array}$ \\
\hline & STANDARDIZE & $\begin{array}{l}\text { - development of instructions, procedures, and } 5 S \text { book } \\
\text { specifying the processes in the company. }\end{array}$ \\
\hline & SUSTAIN & $\begin{array}{l}\text { - proceeding in accordance with internal procedures and } \\
\text { instructions, } \\
\text { - improving the communication process in the enterprise, } \\
\text { - improvement of relations between employees, } \\
\text { - increase in product quality. }\end{array}$ \\
\hline \multirow{5}{*}{$\begin{array}{l}\text { Corrective } \\
\text { and } \\
\text { preventive } \\
\text { actions }\end{array}$} & SORT & $\begin{array}{l}\text { - sort items for necessity and unnecessary, } \\
\text { - removal of unnecessary items. }\end{array}$ \\
\hline & STREIGHTEN & $\begin{array}{l}\text { - proper location of the items at the workplace, } \\
\text { - shortening the time of preparing the workplace for work. }\end{array}$ \\
\hline & SHINE & $\begin{array}{l}\text { - maintaining cleanliness at the workplace, } \\
\text { - maintaining safe working conditions. }\end{array}$ \\
\hline & STANDARDIZE & - compliance with all the rules prevailing in the company. \\
\hline & SUSTAIN & $\begin{array}{l}\text { - self-control, } \\
\text { - cooperation in team-solving problems, } \\
\text { - implementation of decisions of the superiors. }\end{array}$ \\
\hline
\end{tabular}

\section{Tool for supporting implementation of $5 \mathrm{~S}$ method}

In the Figure 7 a proposed scheme is presented that include two main assumptions responsible for implementing $5 S$ method:

1. The scheme was performed as a result from both theoretical model of $5 S$ method and diagnosis what makes the method implementation customized.

2. The mobile devices are proposed to quick order data and establish necessary corrective actions. 


\section{$5 S$ method}

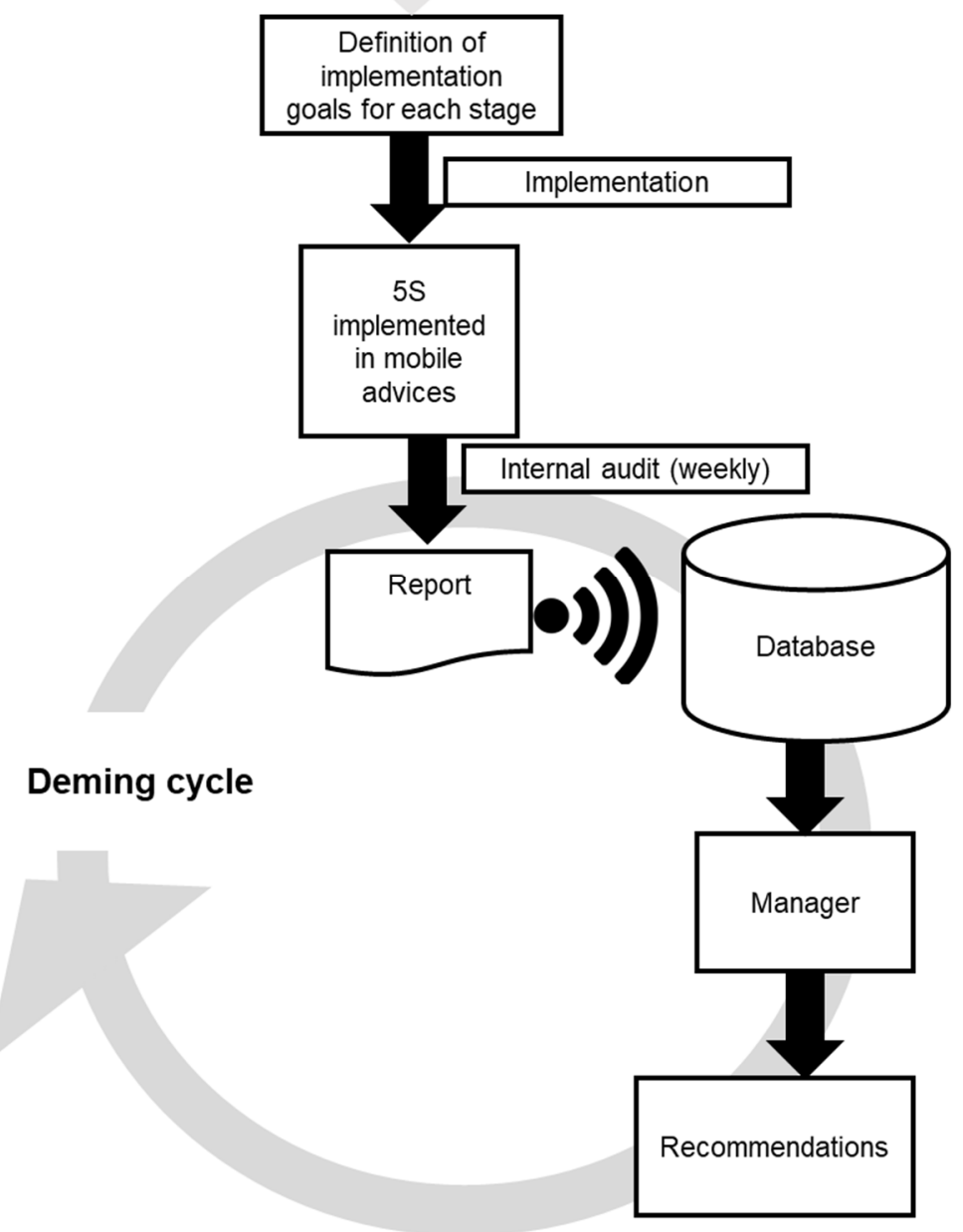

Fig. 7 The implementation of $5 \mathrm{~S}$ methods for production company

One of the innovative ways of conducting an internal audit is functional auditor software synchronized with the company's auditing manager software. In order to unify and streamline the process, an expert for working safety developed the basic questions that verify the significant character of the $5 \mathrm{~S}$ system and permanently introduces them to the software with the possibility of editing. Depending on the answer, the appropriate number of points was assigned to each query. A six-point scale was distinguished:

- 5- Excellent,

- 4-Very good,

- 3-Good,

- 2 - Average,

- 1 - Poor,

- 0 - Very Poor.

The auditor reports all discrepancies by means of photos and short descriptions by using a tablet or phone with software that was developed by the company and is not available on the market (Figure 8). 


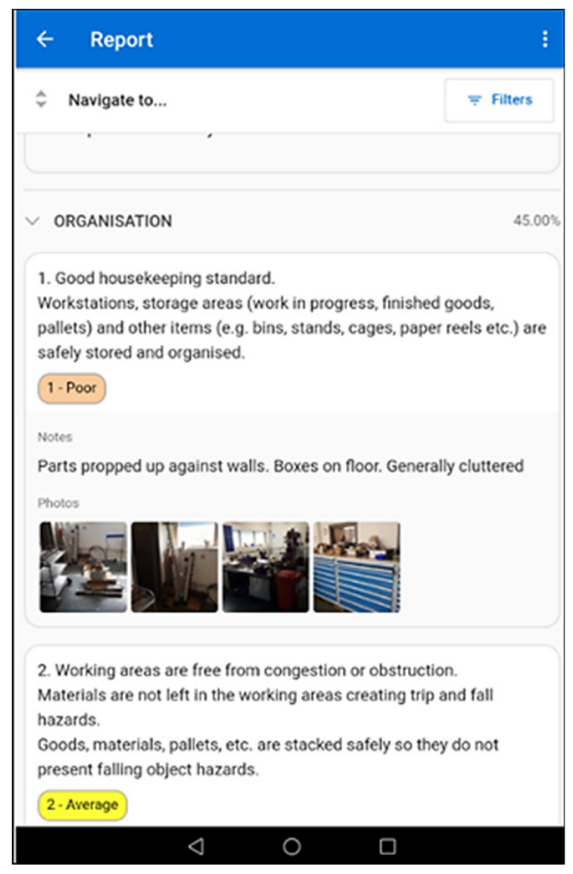

Fig. 8 Audit software

After the audit, a report is generated automatically and the results are sent directly to the person managing the audits and the person responsible for the audited area (area manager). Figure 9 presents the results of the audit.

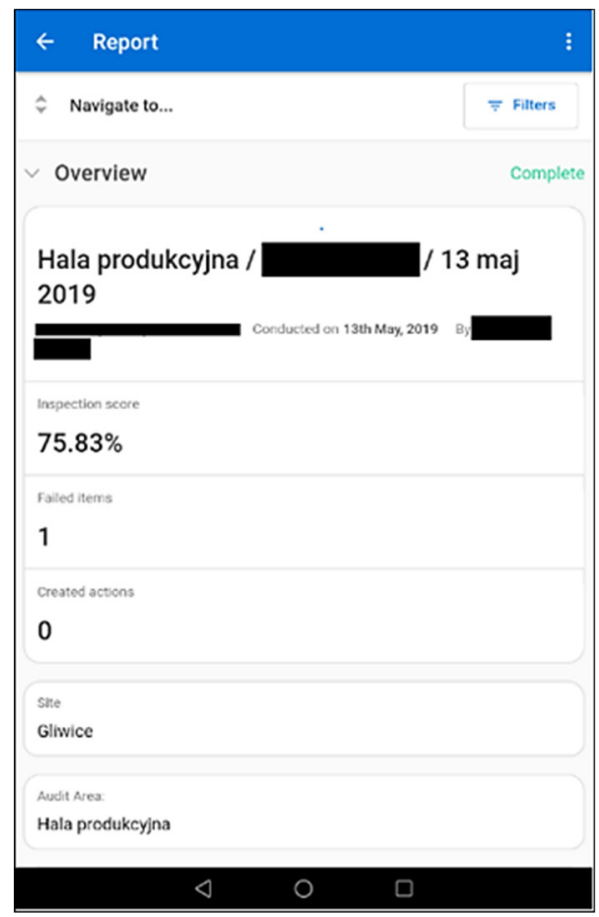

Fig. 9 Audit results

Thanks to the software, the auditor does not lose time to prepare a report, and the person responsible for a given area in the company can quickly react and remove inconsistencies, while the person managing the audits is immediately informed about the correction of irregularities (Figure 10). 


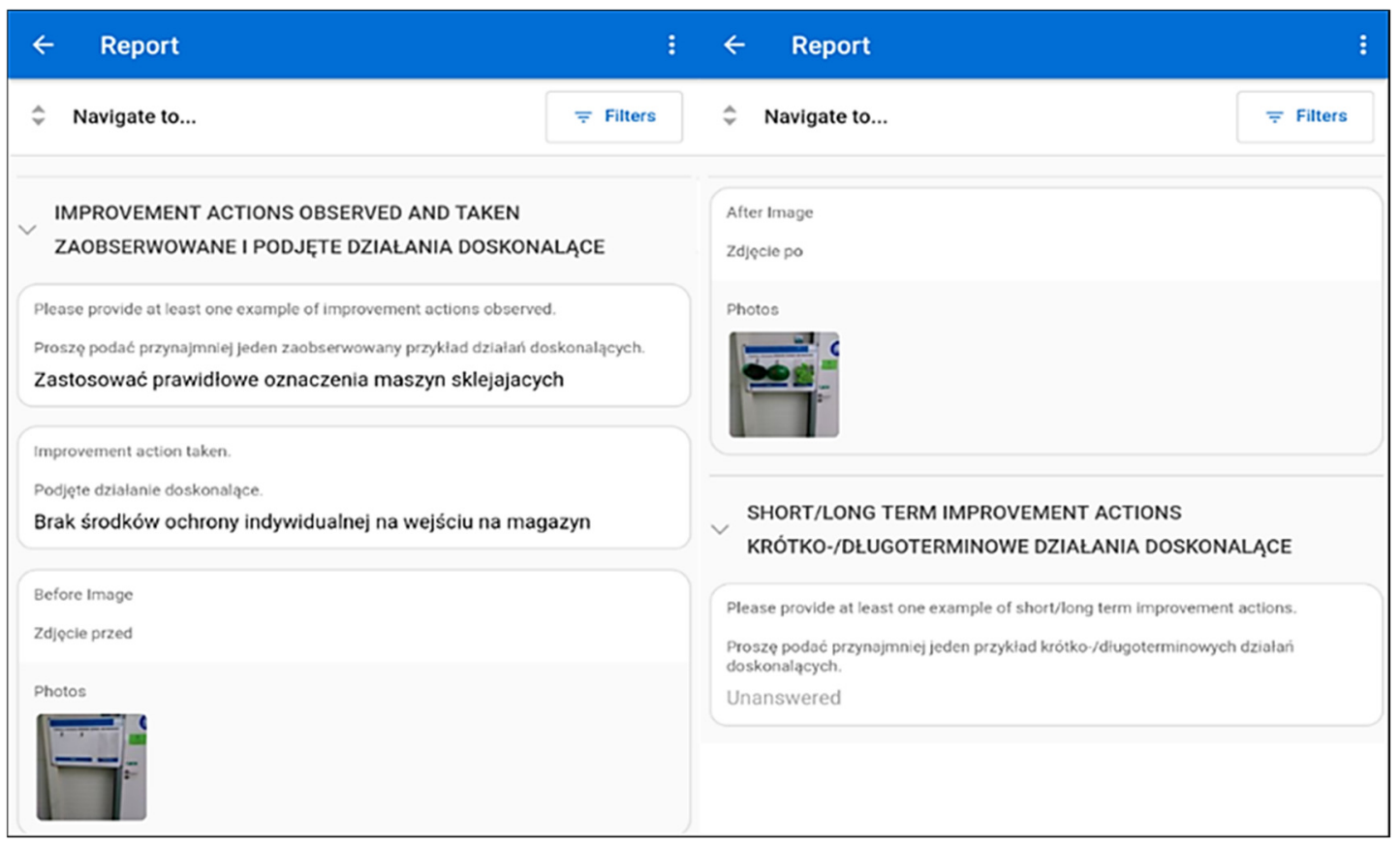

Fig. 10 Improvement actions observed and taken

Such an innovative way of conducting an internal audit is possible in every production enterprise.

\section{CONLUSION}

The implementation of the $5 S$ method brings many benefits to the company. Workstations are organized in accordance with the introduced standard. In addition, the efficiency of work is increased, which is affected by the increase in productivity, increase in the quality of finished products, elimination of waste, less inventory, no downtime. In order for the implementation process to be successful, employees must be involved in building and implementing the standard and developing the habit of self-discipline. The implementation process must be presented in a comprehensible way and preceded by a series of training sessions for all employees.

Based on the analysis of many scientific articles, it can be seen that the $5 \mathrm{~S}$ method has many advantages. In most cases they are individually matched to the area in which the system was implemented. The most important benefits include improving communication between the employee and the manager, maintaining the cleanliness of machines and devices, reducing the number of accidents at work, reducing the changeover time, reducing the number of broken components, reducing the failure of machines and tools.

Successful auditing gives you the opportunity to gain a competitive advantage and quickly develop your business in terms of security. However, in order to implement the $5 \mathrm{~S}$ in full, you need to be persistent in achieving your goals.

It is recommended to develop reference models for the implementation of the $5 \mathrm{~S}$ method divided into individual industries. 


\section{REFEENCES}

Abbott, L. J., Parker, S. and Peters, G. F. (2010). Serving two masters: The association between audit committee internal audit oversight and internal audit activities. Accounting Horizons, 24(1), pp. 1-24.

Ablanedo-Rosas, J.H., Alidaee, B., Moreno, J.C. and Urbina, J. (2010). Quality improvement supported by the $5 \mathrm{~S}$, an empirical case study of Mexican organisations, International Journal of Production Research, 48(23), pp. 7063-7087.

Al-Aomar, R.A. (2011). Applying 5 S lean technology: an infrastructure for continuous process improvement. World Acad Sci, Eng and Technol, 59(12), pp. 2014-2019.

Bayo-Moriones, A., Bello-Pintado, A. and Merino-Díaz de Cerio, J. (2010). 5S use in manufacturing plants - contextual factors and impact on operating performance. Int $\mathrm{J}$ Qual \& Rel Manage, 27(2), pp. 217-230.

Bevilacqua, M., Ciarapica, F.E., De Sanctis, I., Mazzuto, G. and Paciarotti, C. (2015). A changeover time reduction through an integration of lean practices: a case study from pharmaceutical sector. Ass Auto, 35(10), pp. 22-34.

Chapman, C.D. (2005). Clean house with lean 5S. Quality Progress, 38(6), pp. 27-32.

Kaushik, K. and Sanjeev, K. (2012). Step for implementation of 5S. International Journal of Management, 2(6), pp. 402-416.

Kobayash, K., Fishe,r R. and Gapp R. (2008). Business Improvement Strategy or Useful Tool? Analysis of the Application of the 5S Concept in JAPAN, the UK and the US. Total Quality Management, 19(3), pp. 245-262.

Korkut, D.S., Cakıcıer, N., Erdinler, E.S. and Ulay, A.M. (2009). Dogan, 5 S activities and its application at a sample company, African Journal of Biotechnology, 8 (8), pp. 17201728.

Mazur, A. and Gołaś, H. (2010). Zasady, metody i techniki wykorzystywane w zarządzaniu jakością. Poznań: Wyd. Politechniki Poznańskiej.

Paszkowski, W. and Loska, A. (2018). Modelling of noise threat assessment in small industrial rooms. Moderni matematicke metody $v$ inzenyrstvi. Cesko-polsky seminar (3mi). Sbornik z 26. seminare, 22.1.-24.1. 2018, Horni Lomna, pp. 221-229.

Patel, V.C. and Thakkar, H. (2014). Review on Implementation of 5 S in Various Organization, International Journal of Engineering Research and Applications, 4 (3), pp.774-779.

Ramdass, K. (2015). Integrating 5S principles with process improvement: a case study. Portland International Conference on Management of Engineering and Technology, 5 (10), pp. 1908-1917.

Abstract. Currently entrepreneurs have the opportunity to use many methods and tools that support production management, quality and improvement of working safety. A method worth paying attention to is the 5S method, which brings order and discipline to the workplace. The article presents practical aspects of the implementation of the 5S method using five simple steps that give the real benefits to a company. Particularly the specific solutions that can be applied at every stage of the implementation of the $5 \mathrm{~S}$ method is indicated. Also innovative ways of conducting internal audits are presented. In addition, a model for the implementation of the 5S concept was proposed, which supports maintaining the healthy standards at a high level. It has been pointed out that the implementation of $5 S$ rules must be constantly monitored and improved. Therefore, supervision and motivational activities are particularly important, especially from the side of leaders and managers represented an organization.

Keywords: 5S system, audit, efficiency improvement, model, workplace 